\title{
A perspectiva da desinstitucionalização: chaves de leitura para compreensão de uma política nacional de saúde mental alinhada à reforma psiquiátrica \\ Perspective of deinstitutionalization: reading keys to understand a national mental health policy aligned with the psychiatric reform
}

\section{Cláudia Pellegrini Braga \\ (iD) https://orcid.org/0000-0002-6061-7972 \\ E-mail: claudia.braga®usp.br}

Universidade de São Paulo. Faculdade de Filosofia, Letras e Ciências Humanas. Departamento de Filosofia. São Paulo, SP, Brasil.

\section{Correspondência}

Av. Prof. Luciano Gualberto, 315, Cidade Universitária. São Paulo, SP, Brasil. CEP 05508-010.

\section{Resumo}

A perspectiva da desinstitucionalização é considerada eixo organizador da política nacional de saúde mental brasileira em vigor nos anos de reforma psiquiátrica. Dada a reformulação institucional desta política, é relevante compreender tal perspectiva para análises da alteração da lógica das políticas públicas em saúde mental. Em revisão de literatura que objetivou a reconstrução dos argumentos centrais da desinstitucionalização, buscou-se identificar quatro chaves de leitura: circuito do controle, exercício do poder, manter as contradições abertas e instituição aberta/instituição fechada. 0 estudo demonstrou que essas são construídas em inter-relação e colocam a necessidade de: questionar o objeto da psiquiatria; refletir sobre a articulação entre aparatos institucionais que mantêm a segregação e custódia dos desviantes; identificar relações de poder e recusar o mandato social de trabalhadores; operar dialeticamente com as contradições no cotidiano dos serviços substitutivos; $\mathrm{e}$ sustentar a abertura da instituição à multiplicidade de modos de expressão e interação em um processo crítico e atento aos momentos de fechamento. Ressalte-se que essas chaves de leitura são validadas pela ação prática, na construção da liberdade e da cidadania em contextos reais de vida. Para futura reflexão, são apontadas alterações na política de saúde mental que significam uma descontinuidade da perspectiva teórico-prática da desinstitucionalização.

Palavras-chave: Desinstitucionalização; Saúde Mental; Política Pública; Saúde Pública; Revisão. 


\section{Abstract}

The perspective of deinstitutionalization is understood as an organizing axis of the Brazilian mental health policy in the years of psychiatric reform. Considering the policy reformulation, it is relevant to understand this perspective for analyses regarding changes in public mental health policies perspective. A literature review was held aiming the reconstruction of the central arguments of deinstitutionalization perspective, and four reading keys were highlighted: control circuit, power exercise, keeping contradictions open, and open/closed institution. This study has shown that they are interrelated and embedded in practical field, comprising the need to: questioning the object of psychiatry, reflect on the articulation between institutional apparatuses that maintain segregation and custody of deviants; identify power relations and refuse the social mandate of workers; operate dialectically with contradictions in daily practices of substitutive services; and to sustain institution's openness to the multiplicity of modes of expression and interaction, being critical and keeping attention to closing moments. It must be emphasized that it is by practical action that the keys are validated, constructing freedom and citizenship in real life contexts. For future reflection, mental health policy changes that imply a discontinuity of the theoreticalpractical perspective of deinstitutionalization are pointed out.

Keywords: Deinstitutionalization; Mental Health; Public Policy; Public Health; Revision..

\section{Desinstitucionalização como eixo organizador da política nacional de saúde mental}

A reforma psiquiátrica brasileira configura-se como um processo complexo e crítico que envolve a proposição e construção de inéditos saberes, valores, práticas e instituições orientados para a superação do modelo e lógica asilar e para a afirmação dos direitos e da cidadania das pessoas com experiência de sofrimento psíquico (Brasil, 2005, 2016). Este processo engloba princípios e diretrizes traduzidos na construção e implementação de uma política pública e nacional de saúde mental, na promulgação de leis e normativas que estabelecem direitos, com destaque para a Lei 10.216/2001, e na criação de estratégias, práticas e serviços inovadores, abertos e de base territorial, que nos anos de reforma psiquiátrica construíram e consolidaram uma rede de atenção psicossocial substitutiva ao modelo e à lógica asilar (Brasil, 2001, 2015, 2016).

Ainda, o processo de reforma psiquiátrica conta com a importante participação de usuários, familiares e trabalhadores de serviços da rede de atenção psicossocial, além de atores de setores da educação, justiça, assistência social e outros na proposição, articulação e realização de ações. Por meio de trocas sociais e afetivas e em um processo de redistribuição de poder, os diferentes atores sociais que compõem este processo foram construindo no tecido social outras formas de relação com a experiência do sofrimento psíquico. Neste contexto, com ações pactuadas e com base em diálogos democráticos, uma política nacional de saúde mental foi desenvolvida e implementada com o propósito de cuidar em liberdade e criar condições concretas para o exercício de direitos de cidadania, transformando estruturas e culturas com o horizonte da emancipação (Brasil, 2016).

A perspectiva teórico-prática da desinstitucionalização é parte deste processo e envolve a desconstrução e a superação de modos de conhecimento, de formas de relações e práticas violentas e de instituições e aparatos de asilamento e objetificação dos sujeitos nos termos de um diagnóstico psiquiátrico. Ainda, expressa-se na 
invenção de proposições substitutivas destes diversos mecanismos de negação e violação dos direitos do outro, com a construção de um lugar social para a experiência do sofrimento psíquico que signifique defesa, promoção e garantia de direitos de cidadania (Rotelli; De Leonardis; Mauri, 2001).

Os serviços substitutivos aos de lógica asilar e psiquiátrica, com suas práticas cotidianas voltadas para a construção de novas realidades e vias de emancipação, produzindo reverberações nos diversos âmbitos e estruturas sociais, podem ser compreendidos como "instituições para desinstitucionalizar” (Rotelli, 2001, p. 95). Essa perspectiva, construída no contexto da experiência italiana e, mais especificamente, em Gorizia e em Trieste, constituiu um campo de propostas teóricas e práticas na saúde mental, gerando um arcabouço de conceitos e de modos de pensar e produzindo práticas de transformação da realidade (Nicácio, 2003). Ora, no processo de reforma psiquiátrica brasileiro a perspectiva da desinstitucionalização é de tal relevância que foi considerada no Relatório de Gestão 2011-2015 eixo organizador da política nacional de saúde mental (Brasil, 2016, p. 2).

Nesse documento, o último relatório de gestão publicado e com alinhamento a uma política nacional de saúde mental compromissada com a desinstitucionalização, são sugeridas cinco "chaves de leitura para a compreensão da importância do processo de desinstitucionalização em todos os níveis", sendo essas "fundamentais para a superação do modelo asilar": "circuito do controle", "exercício do poder", "manter as contradições abertas", "instituição aberta e instituição fechada" e "ação prática” (Brasil, 2016, p. 2). Ora, se essas são chaves de leitura importantes para compreensão das práticas orientadas para a reforma psiquiátrica e que têm como eixo a desinstitucionalização, torna-se relevante apresentá-las e compreendê-las para que, a partir disso, seja possível produzir e aprofundar diferentes reflexões sobre mudanças na lógica política de saúde mental.

Assim, propõe-se reconstruir os argumentos da perspectiva da desinstitucionalização em sua dimensão teórica com vistas a contextualizar as seguintes chaves de leitura: "circuito do controle", "exercício do poder", "manter as contradições abertas" e "instituição aberta/instituição fechada". Há que se afirmar que o campo de proposições teóricas é indissociável das práticas inovadoras realizadas cotidianamente. Mas porque os limites da proposta deste artigo não possibilitam abarcar as ações práticas e porque prover exemplos práticos poderia reduzir a complexidade das ações práticas, propõe-se dar ênfase às quatro primeiras chaves de leitura citadas, mas tendo em vista que é "em ato, nas relações empíricas, que podemos validar todas essas chaves" (Brasil, 2016, p. 4).

\section{Método}

Como parte de pesquisa que objetivou analisar as internações psiquiátricas de crianças e adolescentes (Braga, 2015), foi feita revisão de literatura (Gil, 2007) que teve como objetivo reconstruir os principais argumentos construídos e desenvolvidos na perspectiva da desinstitucionalização na experiência italiana. Para tanto, foram realizadas todas as etapas descritas por Gil (2007), a saber: escolha do tema da desinstitucionalização; levantamento bibliográfico preliminar; formulação do problema e do objetivo da revisão; elaboração do plano provisório do texto; busca e definição das fontes primárias e secundárias; leitura do material; fichamento; e organização lógica dos argumentos na redação do texto. A partir do resultado dessa pesquisa, foi realizada revisão do texto buscando responder especificamente à seguinte questão: na reconstrução e articulação dos argumentos centrais da perspectiva da desinstitucionalização de tradição basagliana, como são compreendidas as seguintes chaves de leitura: "circuito do controle", "exercício do poder", "manter as contradições abertas" e "instituição aberta e instituição fechada”?

No que diz respeito aos materiais, foram utilizadas as obras de Basaglia (1978, 1979, 1985, 2010e) como fonte primária, tendo sido dada preferência às obras já traduzidas para o português no caso da não existência de tradução utilizou-se as obras na língua original de publicação. Como fonte secundária, foram consultadas obras que contribuem com o debate (Foucault, 2006), além de autores e comentadores que deram continuidade às discussões produzidas por Basaglia no contexto 
italiano e no contexto brasileiro da reforma psiquiátrica (Kinoshita, 1996; Nicácio, 2003; Rotelli, 2001; Rotelli; De Leonardis; Mauri, 2001). Para análise do conjunto dos materiais, foi realizada leitura das obras que constituem fonte primária; considerando a consulta aos materiais relativos à fonte secundária, foi produzida síntese e articulação das ideias e argumentos centrais desenvolvidos na perspectiva da desinstitucionalização. Nesta revisão de literatura foram destacadas as já mencionadas chaves de leitura.

\section{Perspectiva da desinstitucionalização: "gestos elementares"}

A ruptura inaugural em relação às bases do saber psiquiátrico e à prática realizada em manicômios, com a compreensão de que era fundamental romper com a instituição psiquiátrica em si - o que inclui seus aparatos científicos, assistenciais, relacionais, administrativos, legislativos e culturais -, ocorreu no contexto italiano de desinstitucionalização, tendo sido desenvolvidos questionamentos e proposições práticas para transformação da realidade da violência praticada nos manicômios. Em uma atitude crítica em relação ao positivismo como referência epistêmica, à existência dos manicômios, à função dessa instituição e ao mandato social dos profissionais, foi constituído o alicerce da perspectiva de desinstitucionalização.

No questionamento ao modelo positivista de ciência busca-se renunciar a qualquer tentativa de explicar por meio de uma relação de causa e efeito - seja biológica, social e/ou institucional o que seria a experiência de sofrimento psíquico. Ora, considerando o referencial da dialética, Basaglia (1985, p. 124) afirma que a própria matriz "psicopatológica” é "dialética, e não ideológica”, porém a psiquiatria trata a psicopatologia de modo ideológico ao interpretar o sofrimento psíquico como doença, sem problematizá-lo dialeticamente daí afirmar que a desinstitucionalização envolve, dentre outros gestos, descortinar a ideologia psiquiátrica. Nessa linha, Basaglia (1979, p. 79) assinala que o sofrimento psíquico não é um produto orgânico e nem um produto social, mas que: loucura, como todas as doenças, é expressão das contradições do nosso corpo [...], que é orgânico e social [...]. A doença, sendo uma contradição que se verifica no ambiente social, não é um produto apenas da sociedade, mas uma interação dos níveis dos quais nos compomos: biológico, sociológico, psicológico. Dessa interação participa uma enorme quantidade de fatores. (Basaglia, 1979, p. 79)

Tal entendimento ganha consistência nas práticas de desinstitucionalização, em um movimento em que se acentua a necessidade de transformar as relações de poder e são constituídas propostas de ações transformadoras. Trata-se de ações desinstitucionalizantes porque neste processo, a partir da crítica ao modelo existente, foram desconstruídos os modos de saber e de fazer então vigentes e foram criadas formas inéditas de entendimento e relação com a experiência da loucura. Destaca-se que as reflexões produzidas na perspectiva da desinstitucionalização, segundo Basaglia (1978, p. 16), são sempre coletivas, já que "uma discussão é decorrente de um intercâmbio de opiniões”. Nesse processo, compreendeu-se como "gestos elementares" para transformação:

eliminar os meios de contenção; restabelecer a relação do indivíduo com o próprio corpo; reconstruir o direito e a capacidade de uso de objetos pessoais; reconstruir o direito e a capacidade de palavra; eliminar a ergoterapia; abrir portas; produzir relações, espaços e objetos de interlocução; liberar os sentimentos; restituir os direitos civis eliminando a coação, as tutelas jurídicas e o estatuto da periculosidade; reativar uma base de rendimentos para poder ter acesso aos intercâmbios sociais. (Rotelli; De Leonardis; Mauri, 2001, p. 33)

Rotelli, De Leonardis e Mauri (2001, p. 28) destacam, também, a necessidade de reconhecer a complexidade do sujeito em sua "existência global, complexa e concreta" em sua "relação com o corpo social”, desconstruindo, recompondo e recontextualizando o problema; com isso, ao invés de um objeto fictício - o diagnóstico psiquiátrico afirmado como uma doença -, o olhar volta-se para a "existência-sofrimento dos pacientes e sua 
relação com o corpo social" (Rotelli; De Leonardis; Mauri, 2001, p. 30). No projeto basagliano, o sofrimento psíquico passa, então, a ser considerando como uma dimensão da existência humana.

Para Basaglia (2010c, p. 62), a psiquiatria recusa olhar a multiplicidade do sujeito em suas contradições, produzindo diagnósticos que, pautados em uma "incompreensibilidade dos sintomas", adquirem "um valor de categoria, no sentido de que correspondem a um etiquetamento, além do qual não existe mais possibilidade de ação ou saída”. Como consequência dessa inscrição diagnóstica, no momento em que adentra no hospital psiquiátrico o sujeito é "definido como doente, e todas as suas ações, participações e reações são interpretadas e explicadas em termos de doença" (Ongaro Basaglia, 1985, p. 273). Dessa forma, na lógica da instituição psiquiátrica, o diagnóstico psiquiátrico assume o significado de um juízo de valor e é encerrado em um rótulo, o que significa afirmar que, historicamente, "o doente foi isolado e colocado entre parênteses pela psiquiatria", para que fosse possível a dedicação à "definição abstrata de uma doença, da decodificação das formas, da classificação dos sintomas" (Basaglia, 1985, p.125). Na necessária contramão dessa lógica, é preciso fazer a crítica ao saber e à prática psiquiátricos porque estes, calcados em uma perspectiva positivista, reduzem o sujeito e sua complexidade em apenas um objeto: uma afirmada doença.

\section{Perspectiva da desinstitucionalização: circuito do controle e exercício do poder}

Acerca dessa crítica necessária, um ponto a ser destacado sobre a lógica da instituição psiquiátrica refere-se ao fato de que o hospital psiquiátrico expressão mais forte da instituição psiquiátrica contém em seus muros não apenas aqueles sujeitos com experiência de sofrimento psíquico, mas também aqueles que, por a eles ser atribuído algum desvio em relação à norma social, são considerados perigosos ou nocivos para a sociedade (Basaglia, 1985; Foucault, 2006). Nesse sentido, compreender a lógica da instituição psiquiátrica requer refletir sobre como é definida a norma social e quem são os sujeitos considerados desviantes da norma social, sendo a eles atribuída uma suposta periculosidade.
De modo geral, a norma social "é representada pela eficiência e pela produtividade”, sendo que aquilo que é apontado por uma classe dominante na sociedade como ineficiente e improdutivo não tem espaço no tecido social. E é a psiquiatria enquanto ciência que tem a função de

determinar os comportamentos “normais", de definir os limites da norma, de controlar através de terapia e reclusão os desvios, não a partir das necessidades do homem [...], mas como resposta às exigências da lei econômica, as necessidades do grupo dominante, que deve ter sobre seu controle a maioria [desviante], para garantir sua própria sobrevivência. (Basaglia; Ongaro Basaglia, 2013, p. 20)

Com efeito, a ciência e a lei econômica estão entrelaçadas na definição da norma, sendo que a ciência confirma "os limites de norma mais apropriados e úteis à segunda” - ou seja, mais úteis à dimensão político-econômica de uma sociedade de tal modo que a ciência pode "confirmar uma diversidade patológica que é instrumentalizada segundo as exigências da ordem pública e do desenvolvimento econômico, cumprindo sua função de controle social" (Basaglia; Ongaro Basaglia, 201ob, p. 229). Há, pois, uma codificação da experiência humana pela ciência, com a criação de limites nos modos de ser e estar no meio social. Nos momentos em que são definidas as normas sociais - que podem se estreitar ou se alargar nos diferentes contextos socio-históricos - são definidos seus limites e desvios. Com isso, determina-se quem são os sujeitos desviantes.

Nesse sentido, Basaglia e Ongaro Basaglia (2010a, p. 171) definem como desviantes aquelas pessoas que "perderam ou nunca tiveram uma força contratual com as fontes produtoras", que é formada pela classe dominante porque essa tem maior poder econômico, político e social. Porque não dispõe de poder contratual nas relações sociais, o desviante se encontra fora da norma ou no limite dela - sua singularidade, sua subjetividade, suas contradições e seu modo de expressão e relação no mundo não tem lugar para ser compartilhada ou existir no tecido social. Além disso, na lógica específica da instituição psiquiátrica, o que é considerado desvio 
da norma social é afirmado como sofrimento psíquico e é codificado como doença em um diagnóstico psiquiátrico, de modo que os desviantes se tornam duplamente desadaptados. Isso porque, de um lado, são excluídos pela sociedade pelo que é definido como um desvio e, de outro, pela própria psiquiatra, que com conceitos abstratos define que a doença é incurável e incompreensível, sendo o "sintoma principal a periculosidade ou a obscenidade" (Basaglia; Ongaro Basaglia, 2010b, p. 229).

Dessa maneira, segundo Basaglia e Ongaro Basaglia (2010a, p.170), "faz-se coincidir a ideologia do desvio com o problema do desviante" e a resposta científica para o desvio passa a ser a internação em um hospital psiquiátrico - um manicômio ou outra instituição psiquiátrica de características asilares -, onde esse desvio pode ser tutelado e custodiado. A instituição manicomial em sua função de custódia e de segregação, "como todos os locais de internação, não é senão a triste consequência do acobertamento de uma contradição, por meio da ideologia da inelutabilidade e da ininteligibilidade da doença" (Basaglia, 2010f, p. 145).

O saber psiquiátrico é uma resposta ideológica que ao realizar uma racionalização e organização da complexidade e multiplicidade de vida em termos de desvios, categorizados em doenças, de fato em nada altera a realidade, já que não considera as necessidades reais dos sujeitos e as contradições presentes. Basaglia (2010b, p. 203) enfatiza que "ninguém afirma que a doença mental não exista", mas o problema é que a "verdadeira abstração não está na doença, do modo como pode manifestar-se, e sim nos conceitos científicos que a definem sem enfrentá-la como fato real".

Tendo isso em vista, a experiência italiana demonstrou, em um primeiro momento, a importância de colocar em crise a psiquiatria enquanto instituição e enquanto saber, questionando o espaço concreto de tutela e segregação, o manicômio, e o conjunto de saberes abstratos que exercendo uma função social realizavam a manutenção de uma ordem pública e de controle de desvios (Basaglia, 1985). Para além disso, buscou-se compreender a dinâmica entre o manicômio e a sociedade, interrogando-se sobre as práticas sociais que criavam condições para que esta instituição fosse a delegatária do controle e da tutela de pessoas sem poder contratual. Ora, como já assinalado, na manutenção da ordem pública a instituição psiquiátrica ocupa o lugar de custódia dos desvios da norma social. Mas a perspectiva da desinstitucionalização avançou nessa compreensão ao identificar que a instituição psiquiátrica está atrelada a um conjunto de outros aparatos institucionais que operam de modo inter-relacionado para cercear as contradições de vida e os desvios que não têm lugar de expressão no âmbito público. É justamente esta relação recíproca entre aparatos institucionais, como o sistema de saúde, de justiça, de educação, de assistência social e outros, que com práticas orientadas para o controle dos desvios e sustentadas por um contexto social, econômico e político constitui o que se denomina de "circuito do controle" (Basaglia; Gianichedda; Equipe de Trieste, 2010) umas das chaves de leitura da perspectiva da desinstitucionalização (Brasil, 2016).

$\mathrm{O}$ "circuito do controle" diz respeito a esta interrelação estabelecida entre diferentes instituições que “produzem e reproduzem lógicas de normalização impositiva, sempre envolvendo algum nível de uso da força" (Brasil, 2016, p. 3) com vistas a exercer a função de controle. As instituições da violência em geral são lugares de custódia dos desvios, mas no circuito do controle é a instituição psiquiátrica de características asilares o principal aparato que sustenta esse circuito. De acordo com Basaglia, Gianichedda e Equipe de Trieste (2010, p. 246), a instituição psiquiátrica produz "uma série de círculos concêntricos de contágio, correspondentes a outros tantos aparatos institucionais", o que significa dizer que sua existência afirma para a sociedade e para as outras instituições que o único lugar existente para aquilo que é definido como desvio da norma social é dentro de seus muros, alimentando no tecido social uma lógica de segregação. Nesse sentido, o hospital psiquiátrico se apresenta como o "local de escoamento de toda a falha dos demais sistemas de normatização (educação, justiça, saúde, assistência social etc.), e assume a condição de depositário do não normal" (Brasil, 2016, p. 3).

A pessoa que é apreendida no circuito de controle é aquela que não apenas rompe com a ordem social, mas que produz gestos disruptivos em cena pública, 
nos lugares compartilhados da vida em sociedade. Para Basaglia (2010b, p. 202) é significativo o fato de as "sanções mais rígidas sempre caírem sobre quem não dispõe de um espaço privado, onde possa expressar - em segurança - o próprio desvio no momento em que ultrapassa o limite". Basaglia (1985, p. 108) destaca que, antes mesmo da internação, o caminho percorrido por alguém que dispõe de recursos financeiros será diferente de quem é miserável financeiramente, pois o primeiro já desfruta, de antemão, de maior poder de contrato na sociedade. Dessa forma, apesar de ambos serem, pela sociedade, "automaticamente classificados como doente mental 'perigoso para si e para os outros e objeto de escândalo público", a internação em um hospital psiquiátrico - ou uma outra instituição psiquiátrica de características asilares - de uma pessoa que vive em condição de pobreza poderá significar um processo irreversível de desistorização de si e de exclusão social, o que, talvez, não aconteça com quem dispõe de recursos financeiros (Basaglia, 1985, p. 108). Nessa linha de reflexão, é preciso notar que a questão da classe social tem implicações em um processo de internação e institucionalização: a segregação ocorre, também, por uma diferença de classe social e de poder econômico. Com efeito, afirma-se que o hospital psiquiátrico "se destina a administrar o aspecto social da doença mental, e não a doença em si” (Basaglia, 2010f, p. 139).

Basaglia (1978, p. 18) narra que, em sua experiência, ao adentrar em um hospital psiquiátrico como médico, não via de imediato naquelas pessoas uma nosografia psiquiátrica que definia quadros de esquizofrenia, depressão e outros, mesmo em relação às pessoas com sofrimento psíquico. Mas via "pessoas oprimidas ou pessoas atadas, pessoas destruídas, pessoas que pediam para sair, ir às suas casas, e às quais o médico sempre respondia com a mesma expressão", sendo essa expressão a palavra "amanhã"; um "amanhã que não chega nunca, um amanhã que será sempre um hoje de internamento eterno" (Basaglia, 1979, p. 95). Um "amanhã" que é expressão da função social excludente da instituição psiquiátrica e expressa a relação de poder e o papel dos profissionais dessa instituição, na qual o psiquiatra e os outros trabalhadores estão "sempre em uma posição privilegiada de dominante frente ao doente" (Basaglia, 1979, p.14). Essa diferença de poder entre os trabalhadores e as pessoas objetificadas em um diagnóstico psiquiátrico, exercida cotidianamente e combinada com a função social da instituição psiquiátrica, acarreta a presença do traço mais marcante desse equipamento: a violência.

As instituições da violência são aquelas em que há uma clara diferença de poder entre duas partes de uma relação, que se traduz em uma diferença de papel entre servo e senhor (Basaglia, 1985). São exemplos de instituições da violência as instituições psiquiátricas e as prisões que, para Basaglia (1978, p. 16), aproximam-se em suas lógicas, considerando que a ideologia que respalda a problemática da reclusão de ambos os aparatos é a mesma, pois em uma sociedade que segue a lógica da eficiência produtiva "o cárcere protege a sociedade do delinquente, e o manicômio protege a sociedade da pessoa que também desvia das normas". Há uma similaridade entre o hospital psiquiátrico e as prisões enquanto instituição no sentido de que ambas são tidas como instituições racionais que contêm e dão um lugar para o que na sociedade é considerado irracional: o crime e a loucura; é como se o criminoso somente fosse aceito socialmente quando estivesse em uma prisão, assim como o louco só pudesse existir enquanto definido por uma doença em uma instituição psiquiátrica de características asilares. Trata-se de "instituições que servem para manter limites aos desvios humanos, para marginalizar o que está excluído da sociedade" (Basaglia, 1979, p. 45).

O fato de essa lógica ser operada em um hospital psiquiátrico é ainda mais grave, dado que essa instituição supostamente teria como função ser prestadora de cuidado, mas de fato exerce práticas de segregação e violência baseadas em um sistema punitivo-coercitivo. A questão central para se ter em vista é que não é possível que uma mesma instituição se proponha a produzir o cuidado e a violência, porque esses são dois elementos antinômicos de uma situação. Ainda assim, nas instituições psiquiátricas é delegado aos trabalhadores a sustentação dessa ideologia afirmada socialmente como cuidado. No entanto, pelas razões já afirmadas, o que se realiza em suas práticas é a exclusão de um contingente de 
pessoas consideradas desviantes das normas sociais e a adaptação delas por meio do poder técnico e com aval da ciência e da sociedade à "condição de 'objetos da violência”" (Basaglia, 1985, p. 102). Os trabalhadores têm, então, um papel ambíguo e contraditório, que envolve tanto a expectativa de supostamente garantir uma terapêutica e um tratamento quanto a prática efetiva de segregação e controle, defendendo a sociedade do denominado desviante (Basaglia; Ongaro Basaglia, 2010a).

Em síntese, com uma tarefa definida como terapêutica por uma ciência, são os trabalhadores que, por meio de seus mandatos sociais e cristalizados em seus papéis impostos pela própria função da instituição, irão confirmar para a sociedade a objetificação e a exclusão do outro. Esse papel se efetiva acentuadamente nas práticas violentas - como contenções e eletrochoques -, mas, também, cotidianamente na diferença de poder que se estabelece e é exercida na relação entre trabalhadores e as pessoas que se encontram em instituições psiquiátricas, e que por isso também é entendido como prática violenta. Este é um tema de particular importância, o "exercício de poder”, e, justamente, uma das chaves de leitura da perspectiva da desinstitucionalização (Brasil, 2016).

Como afirmado, essas relações de poder são produzidas "tanto a partir de atribuições formais quanto a partir do cotidiano" (Brasil, 2016, p. 3). Ou seja, são produzidas pelo mandato social dos trabalhadores dessas instituições e pelas ações exercidas no dia a dia da instituição psiquiátrica que assujeitam as pessoas que lá adentram, que são as pessoas que dispõem de menor poder na relação. É objetivo prioritário da desinstitucionalização transformar as relações de poder entre instituição e pessoas em todos os contextos em que essas relações acontecem. Assim, para essa chave de leitura, é preciso considerar o poder exercido pelos trabalhadores e também o baixo ou nulo poder de contrato nas trocas sociais das pessoas que são objetificadas em um diagnóstico psiquiátrico.

Acerca disso, pode-se entender o poder contratual, ou a força contratual, como as possibilidades de reconhecimento em um universo social de uma pessoa realizar trocas sociais, a partir de um valor previamente atribuído a cada pessoa. Segundo
Kinoshita (1996), o poder de contrato estabelecese na relação com outras pessoas, por meio de um processo de intercâmbios que se dão em três dimensões principais: a troca de bens, a troca de mensagens e a troca de afetos. No caso daqueles considerados desviantes das normas sociais, esse poder contratual é anulado no jogo de trocas sociais, visto que seus bens são considerados suspeitos, as suas mensagens são tidas como incompreensíveis e seus afetos compreendidos como desnaturados; nesse cenário, as trocas sociais tornam-se impossíveis (Kinoshita, 1996).

No hospital psiquiátrico, em particular, esta relação de "nítida divisão entre os que têm o poder e os que não têm o poder" (Basaglia, 1985, p. 101) se realiza e se traduz em uma relação cotidiana de opressão e de violência que sempre reitera a condição de baixo ou nulo poder contratual das pessoas consideradas desviantes das normas sociais. Nesse sentido, é preciso ter em vista que a diferença de poder é exercitada no dia a dia, e tanto esse baixo ou nulo poder contratual quanto a situação de objetificação que a pessoa que se encontra na instituição psiquiátrica vive serão elementos que comporão a submissão dessa pessoa a um esquema institucionalizante, baseado em um princípio autoritário-hierárquico e determinado pelo regramento do cotidiano.

De acordo com Basaglia (1978), quando se observa o ritmo desta instituição, nota-se que as ações são realizadas para garantia do bom funcionamento da própria instituição, e não como resposta às necessidades reais dos sujeitos. Nesse sentido, a vida de uma pessoa objetificada em uma suposta doença e sem poder contratual, aderindo à lógica, às práticas e ao ritmo da instituição, será a de "ausência de qualquer projeto, a perda de um futuro, a condição permanente de estar à mercê dos outros, sem a mínima inciativa pessoal"; a pessoa terá na instituição "seus dias fracionados e ordenados segundo horários ditados unicamente por exigências organizacionais que - justamente enquanto tais - não podem levar em conta o indivíduo singular e as circunstâncias particulares de cada um” (Basaglia, 2010a, p. 24). Ora, "este é o esquema institucionalizante sobre o qual se articula a vida no manicômio" e através desse esquema pode ser 
que ocorra de a pessoa "objetificar-se nas próprias regras que o determinam" até identificar-se com essas regras (Basaglia, 2010a, p. 25).

Será esse esquema e essa forma de poder que promoverão a institucionalização de quem está em uma instituição psiquiátrica, de modo que, com o seu corpo "vê-se obrigado a aderir a um novo corpo que é o da instituição, negando qualquer desejo, qualquer ação, qualquer aspiração autônoma que o fariam sentir-se ainda vivo e ainda ele mesmo" (Basaglia, 201od, p. 8o). Para o autor, esse processo de institucionalização que ocorre no cotidiano é perceptível, por exemplo, nas expressões registradas em prontuários como "bem adaptado ao ambiente" e "cooperativo". Ainda, vale notar que considerando que a pessoa é "objeto de uma violência institucional que atua em todos os níveis”, na instituição psiquiátrica "qualquer ação contestadora será definida dentro dos limites da doença” (Basaglia, 1985, p. 112). Nesse sentido, também é preciso questionar expressões como "agitado" e "desafiador". Com a perda da liberdade e das possibilidades de trocar afetos, bens e mensagens, há a perda da própria subjetividade; com isso, não raramente o rosto de uma pessoa internada em um hospital psiquiátrico, por exemplo, passa a ser, na descrição de Basaglia (1978, p. 17), um rosto de quem "não diz nada, que se mantém quieto, que tem atitudes passivas e que frente às ordens do enfermeiro, frente às ordens do médico, espera o dia que nunca chegará, o dia de sua saída, o dia de sua alta”. Por isso, para Basaglia (1978, p. 18), "o tempo que não existe representa a vivência no manicômio".

Nessa linha, a "degradação, objetificação e total aniquilamento" que caracterizam a pessoa que se encontra em uma instituição psiquiátrica, antes de ser expressão de uma doença tal como definida pela psiquiatria, são "o produto da ação destruidora de uma instituição” (Basaglia, 1985, p. 113). O que é destrutivo em uma instituição psiquiátrica não é uma ação ou uma técnica específica apenas, mas a própria organização institucional que destitui a pessoa de condições de contratar mensagens, afetos e bens, e a objetifica em um diagnóstico psiquiátrico. Nessa lógica, a pessoa com sofrimento psíquico não é reconhecida como "uma realidade que sofre com muitas necessidades", como alguém que, como qualquer outra pessoa, tem necessidade de se relacionar afetivamente, de fazer escolhas, de se comunicar e de ter liberdade (Basaglia, 1979, p. 53). Como tais necessidades não são reconhecidas e atendidas, a pessoa encontra-se em uma tal situação de miséria material, comunicacional e relacional, que não é possível vê-la antes de se deparar com tal miséria.

Justamente, Basaglia (1979, p. 33), ao descrever a sua experiência com pessoas internadas no hospital psiquiátrico do Juqueri, situado em Franco da Rocha, no Brasil, afirma que "quando entramos em um manicômio temos à nossa frente a miséria”, o que coloca a questão: "como se pode saber se um habitante do Juqueri é louco? A primeira coisa que ele faz quando nos vê é pedir esmola e nos perguntar 'Quando volto para casa?'. Portanto, pode-se concluir que esse sujeito "tem duas características muito importantes: a consciência da prisão e a consciência prática da miséria” (Basaglia, 1979, p. 33). Esses questionamentos e conclusão indicam o caminho necessário na construção de uma outra via, que passa pela garantia da liberdade em todos os sentidos de fazer intercâmbios, de se relacionar, de habitar múltiplos territórios, de fazer escolhas, de ter bens, de ter responsabilidades, de construir projetos, e tantos outros - e, também, pela necessidade de essa "pessoa ter o que comer, ter dinheiro, ter uma cama para dormir” (Basaglia, 1979, p. 31).

E, é por isso que, na transformação de uma instituição como o hospital psiquiátrico - uma instituição da violência -, é preciso partir da ruptura do sistema punitivo-coercitivo e do princípio hierárquico e autoritário e problematizar dialeticamente a situação geral, incluindo a função da própria instituição e dos profissionais desta, negando tudo aquilo que opera com códigos delimitados. A instituição negada é a "tentativa de colocar entre parênteses todos os esquemas, para ter a possibilidade de agir em um território ainda não codificado ou definido" (Basaglia, 1985, p. 29). Aqui, vale destacar que a prática da desinstitucionalização não se refere ao mero fechamento ou reforma do hospital psiquiátrico, mas ao desmonte da lógica da instituição psiquiátrica em todas suas formas 
de expressão, com a superação do modelo asilar e do modo tradicional de olhar e de se relacionar com a experiência de sofrimento psíquico, transformando saberes e práticas e construindo novas possibilidades de viver e existir em um mundo compartilhado. Tal como afirma Rotelli (2001, p. 89), “faz-se necessário repetir algo que para nós é obvio, mas desconhecido para muitos: a instituição que colocamos em questão [...] não foi o manicômio, mas a loucura"; nesse sentido, o que sempre foi colocado em questão foi o "conjunto de aparatos científicos, legislativos, administrativos, de códigos de referência cultural e de relações de poder estruturados em torno de um objeto bem preciso: 'a doença', à qual se sobrepõe no manicômio o objeto "periculosidade"”.

Tendo isso em vista, fica claro que o processo de desinstitucionalização não pode ser concluído apenas com o fechamento dos hospitais psiquiátricos. É preciso ir muito além disso: é necessário desmontar todos os mecanismos que irrompem nas situações de objetificação das pessoas, de internação em instituições psiquiátricas e de institucionalização, mecanismos presentes em diferentes aparatos que constituem um circuito de controle.

\section{Perspectiva da desinstitucionalização: manter as contradições abertas $e$ instituição aberta/instituição fechada}

Dessa forma, na perspectiva da desinstitucionalização, é preciso manter abertas as contradições, que devem ser enfrentadas dialeticamente; e isso só é possível em uma instituição que nega os seus pilares e que se pretende uma instituição em movimento com a permanente abertura de caminhos, lembrando que a "dialética somente existe quando se tem mais de uma possibilidade, quando existem alternativas" (Basaglia, 1985, p. 118). Ora, tem-se aqui a terceira chave de leitura da desinstitucionalização, pois buscar manter as contradições em aberto significa reconhecer que as "contradições são inerentes às relações, sobretudo as institucionais, e implicam a necessidade de respostas dinâmicas e de maleabilidade" (Brasil, 2016, p. 3). Trata-se de reconhecer que em instituições em movimento há "momentos de maior abertura ou fechamento", sendo preciso "recorrer a dispositivos como as reuniões de equipe, as assembleias de usuários, entre outros, cujo sentido é a produção de normas em consenso" para a construção de múltiplas e diversificadas respostas ao longo de um percurso de transformação institucional (Brasil, 2016, p. 4). Esta chave de leitura está intrinsecamente relacionada com a quarta, que trata da "instituição aberta e instituição fechada” (Brasil, 2016, p. 3), pois é pelo horizonte de instituições abertas, porque abertas à multiplicidade de modos de expressão e interação das pessoas, à invenção de inéditas estratégias e ações e à relação com os territórios de vida das pessoas, que é preciso manter as contradições em aberto para produzir respostas singulares, contextualizadas e complexas.

A primeira tarefa dos trabalhadores é a de "negar tudo o que pode dar um sentido predefinido às condutas": a "doença” do outro, o seu próprio mandato social e as suas funções em um hospital psiquiátrico (Basaglia, 1985, p. 29). Nega-se a "doença" ao recusar a "rotulação do doente como “irrecuperável”, a visão do sujeito internado como "um não-homem" e o saber psiquiátrico como a única forma de conhecer o sofrimento psíquico; nega-se o mandato social dos profissionais por esse conferirlhes o papel de defensores da sociedade e da classe dominante; nega-se a função dos profissionais de "simples carcereiros, tutores da tranquilidade da sociedade” (Basaglia, 1985, p. 29). Mais uma vez, tem-se aqui um aspecto central da instituição psiquiátrica: "a coincidência entre o que manda a ciência e o que manda a sociedade" (Basaglia, 1979, p. 15). A partir desse ato de negação, é possível recomeçar "em um território ainda virgem, por cultivar” (Basaglia, 1985, p. 29).

Neste contexto coloca-se o desafio de diante do "fechamento do manicômio" construir a "abertura da instituição" (Brasil, 2016, p. 3). Assim, para transformar a lógica da instituição psiquiátrica é preciso operar dialeticamente com as contradições, mantendo-as em aberto, trabalhando coletivamente os conflitos em busca da invenção cotidiana de novos modos de saber, de fazer e de se relacionar, compondo com espaços e 
contextos diversos e produzindo inéditas normas de modo a alargar as estreitas normas do jogo social. Para tanto, se o norte é a transformação das relações, é preciso "produzir regras, normas e condutas a partir do consenso, da negociação, da mediação, baseadas na participação e no protagonismo" das pessoas, e em particular das pessoas com experiência de sofrimento psíquico, o que envolve necessariamente a redistribuição de poder nas relações (Brasil, 2016, p. 3).

No desmonte da instituição psiquiátrica e de suas formas de expressão é preciso produzir a reciprocidade da relação entre todos, transformando, ao mesmo tempo, as relações interpessoais para redefinir papéis em um processo de reconhecimento de que "não é tanto a doença que está em jogo, mas a carência de valor contratual de um doente”, pois o sofrimento psíquico definido em um diagnóstico tende a implicar um "significado estigmatizante que confirma a perda do valor social do indivíduo" (Basaglia, 1985, p. 107). Como já demonstrado, para Basaglia (1985, p. 107) uma pessoa que se encontra em uma instituição psiquiátrica está estigmatizada independentemente de estar ou não em sofrimento, sendo, a priori, "um homem sem direitos, submetido ao poder da instituição, à mercê, portanto, dos delegados da sociedade (os médicos) que o afastou e o excluiu". Por isso a exigência de nos serviços substitutivos transformar as relações, produzindo liberdade, responsabilidade e reciprocidade, e partindo das necessidades reais das pessoas compreendidas de modo contextualizado como ponto de partida de um processo social complexo de desinstitucionalização, em que as relações entre todos têm como ponto de partida e horizonte a qualidade de serem críticas e dialéticas (Basaglia, 1978).

Trata-se de um desafio contínuo a ser assumido por um coletivo, visto que "as relações institucionais abrem e fecham constantemente” (Brasil, 2016, p. 3), o que coloca a importância de buscar no cotidiano das instituições a construção de relações afetivas, democráticas e éticas entre as pessoas. 0 projeto da desinstitucionalização se realiza, assim, no trabalho que acontece no reconhecimento do outro e de sua "existência-sofrimento" em "relação com o corpo social” (Rotelli, 2001, p. 91), que compreende que "o valor do homem, são ou doente, ultrapassa o valor da saúde ou da doença”, pois “quando o valor é o homem, saúde não pode representar a norma, se a condição humana é a de estar constantemente entre saúde e doença” (Basaglia; Ongaro Basaglia, 2010b, p. 231). Nessa linha, se coloca a necessidade de manter as contradições abertas nas práticas desenvolvidas nos serviços substitutivos à lógica asilar e à ideologia psiquiátrica, trabalhando a partir não mais da lógica problema-solução, mas da possibilidade-probabilidade, com o reconhecimento da complexidade de uma situação que se relaciona com o sofrimento experimentado pelo sujeito em sua vida na relação com o tecido social.

Ainda, na perspectiva da desinstitucionalização reconhece-se que a necessidade basal dos sujeitos é a liberdade. Por isso, afirmar e produzir a liberdade torna-se um ato indispensável na transformação da lógica institucional, de tal modo que o projeto de desinstitucionalização, desde seu princípio, tem como norte assegurar a liberdade não somente das pessoas que se encontram em instituições psiquiátricas de características asilares, mas de todos os envolvidos, pois os trabalhadores dessas instituições podem reconhecer nesse processo a sua própria condição de exclusão, posto que estão "objetificados no papel de excludentes" (Basaglia, 1985, p. 96). Isso significa a abertura de possibilidade de recusa de seus mandatos sociais e de exercício de outras escolhas relacionais; quando se transforma a relação de objetificação do outro, todos - antes, servo e senhor - podem transformar-se no processo.

Nessa linha, parte-se do sujeito com experiência de sofrimento psíquico que é quem contesta o saber e a prática da psiquiatria e, recusando a ideologia psiquiátrica, trabalha-se com vistas a desenvolver uma prática pautada nas necessidades concretas e reais do sujeito, contextualizadas e articuladas com sua história de vida, seus modos de comunicação e expressão no mundo, suas relações e modos de participação nas trocas sociais, e seus projetos de vida; nesse cenário, busca-se a reconquista de sua liberdade, de seus direitos e de sua responsabilidade. Como afirma Ongaro Basaglia (1985, p. 274), no plano prático, a transformação da instituição significará romper com o sistema punitivo-coercitivo e com o princípio 
autoritário-hierárquico, transformando as relações; ao mesmo tempo, significará construir vias para garantia de que, no horizonte da liberdade, essas pessoas possam se "sentir livres para escolher entre um certo número de alternativas possíveis”. Dito de outro modo, "é fundamental que seja considerado o exercício de poder do usuário, possibilitando que ele tenha voz e volte a assumir a responsabilidade sobre as decisões e condutas de sua vida" (Brasil, 2016, p. 4).

Assim, em uma relação dialética que trabalha com as contradições vigentes, a desinstitucionalização passa a ser um processo social crítico e complexo de contínua invenção e transformação da realidade, sem modelos definidos a priori e que luta contra a cristalização das respostas, "a fim de constantemente reabrir interrogações e processos críticos sobre a demanda e sobre a necessidade" (Basaglia; Gianichedda; Equipe de Trieste, 2010, p. 251). Ora, no projeto e na prática da desinstitucionalização, ao se reconstruir a complexidade do objeto, demanda-se a criação de inéditas instituições que estejam “à altura do objeto, que não é mais um objeto em equilíbrio, mas está, por definição (a existência-sofrimento de um corpo em relação com o corpo social), em estado de não equilíbrio: esta é a base da instituição inventada (e nunca dada)" (Rotelli, 2001, p. 91). Nesse sentido,

se um trabalho funda-se na realidade e em suas contradições, sem pretender construir um modelo que confirme e codifique as próprias hipóteses, traz em si a marca do diletantismo veleidoso relativamente a tudo aquilo que ainda não está incluído na norma, e leva ao paradoxo de uma situação dialética, sempre em movimento. (Basaglia, 1985, p. 10)

A instituição inventada está, portanto, sempre em movimento. Os serviços substitutivos estão sempre em movimento. A ideia da instituição aberta/ instituição fechada envolve reconhecer que qualquer serviço, inclusive os serviços substitutivos que são “instituições para desinstitucionalizar", por vezes enfrentam períodos de maior fechamento e por vezes de maior abertura, sendo preciso, assim, uma constante reinterrogação por parte dos que produzem os serviços no sentido de refletir se, de fato, estão sendo construídas trocas plurais na relação com o território e se está se produzindo vida e emancipação.

Trata-se de um processo contínuo que compreende que é a partir dos diversos encontros cotidianos entre sujeitos, constituídos por relações democráticas e éticas que buscam o diálogo e o reconhecimento das necessidades reais e das contradições existentes, que se constroem socialmente novas formas de se relacionar com a experiência do sofrimento psíquico e possibilidades inéditas de cuidado; trata-se, assim, da possibilidade de essa experiência ter espaço de expressão e de trocas plurais no tecido social, em um trabalho que se constitui na afirmação e construção da liberdade e da cidadania em um comum. Nesse sentido, se assinala que o que se busca em processos que tem como perspectiva a desinstitucionalização é a construção conjunta de novas possibilidades que operam em todas as dimensões para que todos possam existir no mundo compartilhado na condição de cidadãos; a "emancipação, portanto, é necessariamente coletiva” (Brasil, 2016, p. 4).

\section{Descontinuidade da política nacional de saúde mental, álcool e outras drogas na perspectiva da desinstitucionalização: apontamentos para futuras análises}

Em dezembro de 2017 foram publicadas a Portaria $n^{0} 3.588 / 2017$ e a Portaria Interministerial $n^{0}$ 2/2017 (Brasil, 2017a, 2017b). Essas publicações são um marco inicial de mudanças da política nacional de saúde mental, álcool e outras drogas, sendo institucionalizada a alteração de sua lógica (Braga, 2018). Frise-se que o conjunto de mudanças na política não se restringe a essas normativas. Há outras normas legais, publicações e ações institucionais realizadas antes e depois da publicação dessas portarias, como a Lei ${ }^{\circ}{ }^{0}$ 13.840/2019 (Brasil, 2019), que impactam na continuidade dessa política como um todo. Ainda, ressalte-se que as mudanças se situam em um contexto político e social ampliado, com destaque para a aprovação da Emenda Constitucional 95, em dezembro de 2016, que em médio e longo prazo 
impactará a continuidade de oferta e de qualidade dos serviços de saúde como um todo pelo desinvestimento e precarização dos serviços públicos ofertados.

Agora, considerando aqui especificamente as portarias citadas para apontamentos iniciais sobre a descontinuidade da lógica e eixo organizador da política pública de saúde mental antes em vigor, destaca-se que por meio da Portaria $n^{0}$ 3.588/2017 foram estabelecidas a inclusão dos hospitais psiquiátricos na rede de atenção psicossocial e a criação de ambulatórios como pontos de atenção da rede de atenção psicossocial; soma-se a essas alterações o aumento de incentivo financeiro aos hospitais psiquiátricos. Ora, a inclusão dos hospitais psiquiátricos na rede de atenção e incentivo de sua continuidade significa a afirmação e validação enquanto política de Estado da função dessas instituições. Sendo o hospital psiquiátrico a expressão mais forte de um paradigma da psiquiatria, é evidente que há um alinhamento com este paradigma e um rompimento com a perspectiva da desinstitucionalização. A criação de ambulatórios, por sua vez, pode desmantelar a lógica territorial de atenção, retirando dos serviços substitutivos territoriais o papel central de tomada de responsabilidade pelas ações de saúde mental de um território e pela atenção global da pessoa. Além disso, é preciso questionar qual a proposta de trabalho em ambulatórios, visto que tendencialmente está alinhada ao paradigma da psiquiatria, com a redução e separação artificial do sofrimento do sujeito de sua relação com o tecido social, apresentando mecanicamente respostas simplificadas para questões complexas. Ainda, é preciso considerar que uma vez que essas duas modalidades de serviço - hospitais psiquiátricos e ambulatórios - passem a operar na rede de serviços, pode ser que um sistema paralelo seja criado, no sentido de que um sujeito entre em um circuito de serviços que envolva apenas atendimento ambulatorial e internação em hospital psiquiátrico: trata-se, enfim, da afirmação da instituição da psiquiatria como eixo organizador de um sistema.

Acrescenta-se a este contexto a publicação da Portaria Interministerial $n^{0} 2 / 2017$, que instituiu um comitê gestor interministerial para atuar no desenvolvimento de políticas públicas voltadas para pessoas com necessidades decorrentes do uso e abuso de álcool e outras drogas, com clara priorização das instituições denominadas de comunidades terapêuticas, e as subsequentes articulações, publicações institucionais e mudanças legais e normativas que criam e ampliam vagas em comunidades terapêuticas, incrementam os incentivos financeiros para estas instituições e alteram a lógica de uma política voltada para essa população. Trata-se mudanças tão profundas que não cabe aqui serem apresentadas e discutidas. 0 que vale ser apontado é uma reflexão sobre normas sociais: para além do campo de interesses políticos em jogo, é preciso em futuras análises considerar como são consideradas, hoje, as pessoas com necessidades decorrentes do uso e abuso de álcool e outras drogas. Como explicado, as normas sociais são alargadas ou estreitadas nos diferentes contextos sociais, sendo definidas pessoas ou grupos como desviantes das normas, para os quais a resposta é a segregação em espaços isolados do restante da sociedade. Se hoje, ainda mais fortemente do que antes, essas pessoas são consideradas desviantes das normas sociais, é preciso questionar não apenas a resposta (comunidades terapêuticas) imposta, mas, tal como proposto na perspectiva da desinstitucionalização, o conjunto de aparatos que sustentam essa resposta.

O que é fundamental notar é que, mais do que uma mudança na organização da rede de serviços, essa alteração significa um rompimento com uma política nacional de saúde mental, álcool e outras drogas de perspectiva desinstitucionalizante. Ora, o que a desinstitucionalização questiona, além da estrutura do hospital psiquiátrico e de instituições de características asilares em geral, são os aparatos que produzem e sustentam certo entendimento e modo de ação em relação ao que é a loucura e, no geral, ao que é definido como desvio da norma, e que apresentam como resposta a segregação social. O que a perspectiva teóricoprática da desinstitucionalização propõe e constrói são novas formas de entendimento e de relação críticas e substitutivas a ideologia psiquiátrica, sendo os próprios serviços abertos, de base 
territorial e substitutivos a essa ideologia uma dentre a multiplicidade de respostas produzidas que criam um novo lugar social para a experiência de sofrimento e tem como ponto de partida a afirmação da cidadania e dignidade dos sujeitos.

A ideologia psiquiátrica é questionada e criticada porque no gesto de objetificação do sujeito em um diagnóstico psiquiátrico - que em si é uma violência porque retira o outro do próprio lugar de sujeito são providas respostas simplificadas de modo que as necessidades reais do sujeito, as histórias e as relações sociais que envolvem e produzem complexas situações não são consideradas. O discurso dessa ideologia retira o próprio sujeito do seu contexto de vida, história, necessidades e sofrimento. Vale afirmar que por ideologia, aqui, entende-se um processo de "ocultamento da realidade social" e a crítica à ideologia consiste em "preencher as lacunas, os silêncios do pensamento e discurso ideológicos, obrigando-os a dizer tudo que não está dito" (Chauí, 2008, p. 118).

Assim, a reintrodução dos hospitais psiquiátricos como parte da rede de atenção psicossocial, a aposta em lógicas ambulatoriais de atenção que rompem com o trabalho nos territórios e o incentivo massivo a comunidades terapêuticas no lugar de ampliar a atenção a serviços substitutivos expressa e transmite uma mensagem: a de que a lógica da política nacional de saúde mental mudou, não sendo mais a desinstitucionalização seu eixo organizador.

\section{Considerações finais}

Este artigo apresenta um limite na compreensão da perspectiva da desinstitucionalização que é, justamente, o de não abordar a quinta chave de leitura proposta: a "ação prática”. Por isso, reitera-se, que é por meio da ação prática que a tão mencionada transformação - do objeto, dos saberes, das instituições, das práticas - pode ocorrer. Na prática cotidiana realizada em cada um dos serviços substitutivos que compõe a rede de atenção psicossocial e na relação entre esses serviços é possível sustentar a produção de cuidado e construir a cidadania nos contextos e cenários reais de vida, mobilizando energias e afetos para a invenção de estratégias singulares e coletivas voltadas para a transformação de todos nesse processo.

Assim, no cotidiano dos serviços e pela ação prática, podem ser constituídos mandatos éticos: inéditos mandatos sociais para os trabalhadores voltados para a produção de novas formas de relação entre todos os envolvidos, em uma perspectiva de ampliação das possibilidades de emancipação de todos e de constituição de territórios de vida em que as contradições e as diferenças tenham espaço de expressão. É apenas por meio da ação prática que a instituição pode ser inventada e reinventada, e quem constrói tais práticas são os atores sociais que fazem parte dos serviços substitutivos.

\section{Referências}

BASAGLIA, F. La institucionalización

psiquiátrica de la violencia. In: BASAGLIA, F. et al. Razón, locura y sociedad. Argentina:

Siglo XXI, 1978. p. 15-34.

BASAGLIA, F. A psiquiatria alternativa: contra o pessimismo da razão, o otimismo da prática. São Paulo: Brasil Debates, 1979.

BASAGLIA, F. A instituição negada: relato de um hospital psiquiátrico. Rio de Janeiro: Graal, 1985.

BASAGLIA, F. A destruição do hospital psiquiátrico como lugar de institucionalização. In: BASAGLIA, F. Escritos selecionados em saúde mental e Reforma Psiquiátrica. Rio de Janeiro: Garamond, 2010a. p. 23-34.

BASAGLIA, F. A maioria desviante. In: BASAGLIA, F. Escritos selecionados em saúde mental e Reforma Psiquiátrica. Rio de Janeiro: Garamond, 2010b. p. 187-224.

BASAGLIA, F. Apresentação a Che cos'é la psichiatria? In: BASAGLIA, F. Escritos selecionados em saúde mental e Reforma Psiquiátrica. Rio de Janeiro: Garamond, 2010c. p. 61-72.

BASAGLIA, F. Corpo e instituição: considerações antropológicas e psicopatológicas em psiquiatria institucional. In: BASAGLIA, F. Escritos selecionados em 
saúde mental e Reforma Psiquiátrica. Rio de Janeiro: Garamond, 2010d. p. 73-9o.

BASAGLIA, F. Escritos selecionados em saúde mental e Reforma Psiquiátrica. Rio de Janeiro: Garamond, 2010e.

BASAGLIA, F. Introdução a Asylums. In: BASAGLIA, F. Escritos selecionados em saúde mental e Reforma Psiquiátrica. Rio de Janeiro: Garamond, 2010f. p. 133-150.

BASAGLIA, F.; GIANICHEDDA, M.; EQUIPE DE TRIESTE. O circuito do controle: do manicômio à descentralização psiquiátrica. In: BASAGLIA, F. Escritos selecionados em saúde mental e Reforma Psiquiátrica. Rio de Janeiro: Garamond, 2010. p. 237-258.

BASAGLIA, F.; ONGARO BASAGLIA, F. A doença e seu duplo: propostas críticas sobre o problema do desvio. In: BASAGLIA, F. Escritos selecionados em saúde mental e Reforma Psiquiátrica. Rio de Janeiro: Garamond, 2010a. p. 161-186.

BASAGLIA, F.; ONGARO BASAGLIA, F. A utopia da realidade. In: BASAGLIA, F. Escritos selecionados em saúde mental e Reforma Psiquiátrica. Rio de Janeiro: Garamond, 201ob. p. 225-236.

BASAGLIA, F.; ONGARO BASAGLIA, F. (Ed.). Crimini di pace: ricerche sugli intellettuali e sui tecnici come addetti all'oppressione. Milão: Baldini \& Castoldi, 2013.

BRAGA, C. A permanência da prática de internação de crianças e adolescentes em instituição psiquiátrica em um cenário de avanços da reforma psiquiátrica: o circuito do controle. 2015. Dissertação (Mestrado em Medicina Preventiva) - Universidade de São Paulo, São Paulo, 2015.

BRAGA, C. Le conseguenze dei mutamenti della situazione politica del Brasile sulla riforma psichiatrica. In: RAVAZINNI, M.; SARACENO, B. (Ed.). Prima le persone. Milano: Il Saggiatore, 2018. p. 45-62.

BRASIL. Lei n ${ }^{0}$ 10.216, de 6 de abril de 2001. Dispõe sobre a proteção e os direitos das pessoas portadoras de transtornos mentais e redireciona o modelo assistencial em saúde mental. Diário Oficial da União, Brasília, DF, p. 2, 9 abr. 2001.

BRASIL. Ministério da Saúde. Reforma Psiquiátrica e política de saúde mental no Brasil. Brasília, DF, 2005.

BRASIL. Ministério da Saúde. Saúde mental em dados. Brasília, DF, ano 10, n. 12, 2015. Disponível em: https://bit.ly/2HuaglJ. Acesso em: 2 out. 2019.

BRASIL. Ministério da Saúde. Saúde mental no SUS: cuidado em liberdade, defesa de direitos e Rede de Atenção Psicossocial: relatório de gestão 2011-2015. Brasília, DF, 2016.

BRASIL. Portaria $\mathrm{n}^{0} 3.588$, de 21 de dezembro de 2017. Altera as Portarias de Consolidação $\mathrm{n}^{0} 3$ e $n^{0} 6$, de 28 de setembro de 2017, para dispor sobre a Rede de Atenção Psicossocial, e dá outras providências. Diário Oficial da União, Brasília, DF, 22 dez. 2017a. Seção 1, p. 236-238.

BRASIL. Portaria Interministerial $n^{0} 2$, de 21 de dezembro de 2017. Institui o Comitê Gestor Interministerial para atuar no desenvolvimento de programas e ações voltados à prevenção, à formação, à pesquisa, ao cuidado e à reinserção social de pessoas com transtornos decorrentes do uso, abuso ou dependência de substância psicoativa. Diário Oficial da União, Brasília, DF, 22 dez. 2017b. Seção 1, p. 104.

BRASIL. Lei $\mathrm{n}^{0} 13.840$, de 5 de junho de 2019. Altera as Leis n ${ }^{0}$ 11.343/2006, 7.560/1986, 9.250/1995, 9.532/1997, 8.981/1995, 8.315/1991, 8.706/1993, 8.069/1990, 9.394/1996 e 9.503/1997 e os Decretos-Lei no 4.048/1942, $8.621 / 1946$ e 5.452/1943 para dispor sobre o Sistema Nacional de Políticas Públicas sobre Drogas e as condições de atenção aos usuários ou dependentes de drogas e para tratar do financiamento das políticas sobre drogas. Diário Oficial da União, Brasília, DF, 6 jun. 2019.

CHAUÍ, M. O que é ideologia? São Paulo: Brasiliense, 2008.

FOUCAULT, M. O poder psiquiátrico. São Paulo: Martins Fontes, 2006. 
GIL, A. P. Como elaborar projetos de pesquisa. São Paulo: Atlas, 2007.

KINOSHITA, R. T. Contratualidade e reabilitação psicossocial. In: PITTA, A. Reabilitação psicossocial no Brasil. São Paulo: Hucitec, 1996. p. 55-59.

NICÁCIO, F. Utopia da realidade: contribuições da desinstitucionalização para a invenção de serviços de saúde mental. 2003. Tese (Doutorado em Saúde Coletiva) - Universidade Estadual de Campinas, Campinas, 2003.

ONGARO BASAGLIA, F. Transformação institucional e objetivos comuns. In:
BASAGLIA, F. A instituição negada: relato de um hospital psiquiátrico. Rio de Janeiro: Graal, 1985. p. 273-283.

ROTELLI, F. A instituição inventada. In: NICÁCIO, F. (Org.). Desinstitucionalização. São Paulo:

Hucitec, 2001. p. 89-100.

ROTELLI, F.; DE LEONARDIS, O.; MAURI, D. Desinstitucionalização, uma outra via: a reforma psiquiátrica italiana no contexto da Europa Ocidental e dos "países avançados". In: NICÁCIO, F. (Org.). Desinstitucionalização. São Paulo: Hucitec, 2001. p. 17-6o.

\section{Agradecimentos}

Agradeço à professora doutora Ana Flávia Pires Lucas D'Oliveira, da Universidade de São Paulo, pela orientação na pesquisa de origem deste artigo, e ao professor doutor Roberto Kinoshita Tykanori, da Universidade Federal de São Paulo, pelo diálogo e pelas sugestões.

Recebido: $27 / 06 / 2019$

Aprovado: 05/09/2019 